\title{
A COMBINATION OF DISCRETE EVENT SIMULATION AND MULTI-CRITERIA ANALYSIS TO CONFIGURE SUGARCANE DROP AND HOOK DELIVERY SYSTEMS
}

\author{
Danilo A. F. de Faria ${ }^{1}$, Márcia L. da S. Frazão ${ }^{1}$, José G. V. Vieira ${ }^{1}$, João E. A. R. da Silva ${ }^{*}$, \\ Paula H. Lemos ${ }^{1}$ \\ ${ }^{2 *}$ Corresponding author. Universidade Federal de São Carlos/ Sorocaba - SP, Brasil. \\ E-mail: jesilva@ufscar.br| ORCID ID: https://orcid.org/0000-0002-6739-5065
}

\section{KEYWORDS}

drop and hook, multicriteria analysis, simulation model, sugarcane, transport.

\begin{abstract}
This article explores decision analysis regarding Drop and Hook (D\&H) transportation operations at sugarcane mills. By means of a case study, a combination of a discrete event simulation model and multi-attribute utility theory was used to evaluate different configurations for sugarcane delivery systems using internal, external, or no D\&H systems. A D\&H strategy maximises truck utilisation, as semi-trailers can be handled independently of the traction unit of the trucks, which makes the transport system more agile. For internal D\&H systems the semi-trailer detaching/attaching point is located inside the mill site while for external D\&H systems it is located outside, before the trucks' weighbridge. Each configuration requires different infrastructure which affects the supply of sugarcane for milling. The case study was applied to a sugarcane mill of a corporation located in São Paulo State. By means of discrete simulation, we determined that eighteen D\&H configurations were feasible. By using the swing weighting multi-criteria decision analysis (MCDA) method, we identified fleet cost as the most important factor, while configurations with external D\&H systems showed the best utility values. For this case study, the best configuration is to use the external D\&H strategy with 28 road trains (truck and two semi-trailers), 12 additional semi-trailer sets, and 6 tractor units.
\end{abstract}

\section{INTRODUCTION}

The sugarcane supply chain aims to grow, harvest, transport, and process sugarcane from the field to the mill (Kadwa \& Bezuidenhout, 2015). An important challenge is how to coordinate the discrete arrivals of the loaded trucks and the continuous processes of the mills, which is commonly resolved by keeping sugarcane stock. However, owing to the perishability, this stock should be processed as soon as possible to avoid quality loss (Iannoni \& Morabito, 2006; Higgins \& Davies, 2005; Silva et al., 2011; Lamsal et al., 2017).

As sugarcane that has been chopped into billets is not usually stocked on the floor for quality purposes, one alternative is to use stock on wheels, enabled by a Drop and Hook (D\&H) strategy. This strategy can be implemented with a truck configuration consisting of a traction unit (truck) separate from the load units (semi-trailers), such as road trains (truck and two semi-trailers). A D\&H system starts when the driver detaches (drops) one set of semitrailers and attaches (hooks) another set of semi-trailers. Semi-trailers loaded with sugarcane feed the mill while the empty ones are pulled by trucks to the farms to be loaded again. In general, the D\&H trip duration is shorter than the regular operation without $\mathrm{D} \& \mathrm{H}$, because for the latter the driver has to wait while the truck is unloaded. Consequently, to enable a D\&H strategy there must be a number of semi-trailers sets in reserve and dedicated tractor units available to move them.

At sugarcane mills, this strategy can be implemented in one of two ways: before or after the weighing and sampling processes, which we will call 'external D\&H' (Figure 1a) or 'internal D\&H' (Figure 1b) systems, respectively. The difference between these systems is that in the internal D\&H system the driver goes through the weighing and sampling processes, drops the full semi-trailer set in the internal yard, hooks the empty set, goes through the tare weighing and then returns to the harvesting areas. In the external D\&H system, the driver drops the full semi-trailer set and hooks the empty set in the yard before the weighing and sampling processes, leaving the remaining processes to the dedicated tractor units. As the truck driver goes through fewer processes, there is a need for additional dedicated tractor units inside the mill to perform the internal operations.

\footnotetext{
${ }^{1}$ Universidade Federal de São Carlos/ Sorocaba - SP, Brasil.

Received in: 10-17-2018

Accepted in: 1-21-2019
} 

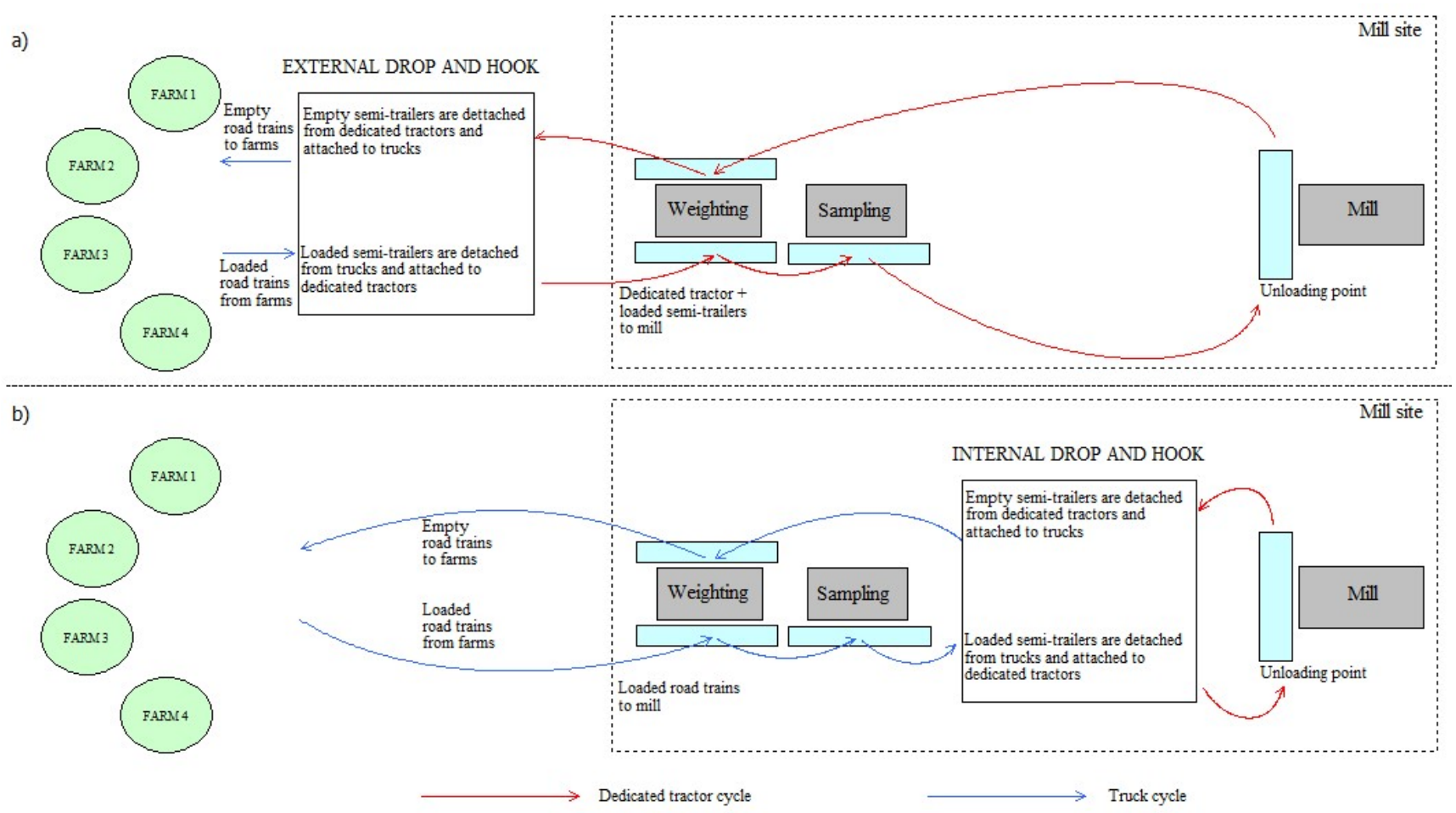

FIGURE 1. External and Internal Drop and Hook systems at sugar mills.

Some applications of D\&H systems have been reported for the steel industry (Cheng et al., 2010), biomass transport (Craige et al., 2016), and also for the sugar and alcohol industry (Iannoni \& Morabito, 2006).

The inbound logistics system at mills is critical for sugarcane milling and its planning, resulting in higher opportunity, labour and fuel costs when the system is idle owing to a shortage of sugarcane (Iannoni \& Morabito, 2006), and when the suppliers do not contribute to the production process efficiency (Soliani \& Pizzinatto, 2015). Sugar mill transit officers often prefer to keep a queue of vehicles loaded with sugarcane near unloading points, to minimize the idle time of the mill (Higgins, 2006). Depending on how the D\&H system has been designed, the infrastructure (trucks, semi-trailers and tractors) required to handle the sugarcane milling process varies substantially. Thus, harvesting and transportation are key steps in the sugarcane supply chain, determining the consistency of supply to the sugar mills (Junqueira \& Morabito, 2017).

When decision makers (DMs) face a complex problem regarding the delivery of sugarcane to the mill, it may be difficult to analyse each variable separately, in which case a discrete simulation model could be beneficial. According to Law (2007), if the mathematical logic of the simulation respects the behaviour of the system studied, it is possible to develop theories and hypotheses based on the analysed events and evaluate the different results generated by changes in the system, thus aiding the decision-making processes, as highlighted by Ram \& Montibeller (2013).

Simulation models have been used to study many aspects of the sugar and alcohol industry, such as fleet sizing (Higgins \& Davies, 2005), work shift scheduling (Silva et al., 2011), and the unloading process inside the sugar mill (Iannoni \& Morabito, 2006). Combining other methodologies with a discrete event simulation model can enhance its capacity of supporting decision-making. In this way, multi-criteria decision analysis (MCDA) can be used to evaluate the results of discrete event simulation and analyse the trade-offs between the decision-making criteria (Saravanan \& Thakkar, 2018; Brito et al., 2012). Ishizaka \& Siraj (2018) evaluated the benefits of using a variety of MCDA tools with an incentive-based experiment in which participants were asked to compare five coffee shops. Although the benefits of different MCDA tools varied, all the tools were found to be beneficial in the sense that, when DMs decided to change their ranking, they followed the recommendation of the MCDA tool. Anojkumar et al. (2014) evaluated different multi-criteria methods based on the fuzzy analytical hierarchy process (FAHP), e.g. FAHPTOPSIS, FAHP-VIKOR, FAHP-ELECTRE, and FAHPPROMETHEE, for selecting pipe material in the sugarcane industry, considering five alternatives and seven criteria.

Brito et al. (2012) used a simulation model to support strategic decisions related to planning and sizing of logistics and production facilities in a Brazilian steel plant. Based on the results of the simulation model, MCDA was used to rank ten feasible scenarios. As pointed out by the authors, discrete event simulation analysis is usually based on a single criterion, such as minimum total cost or maximum profit margin. Therefore, MCDA provides an effective option for complementing the simulation approach.

This study aims to combine the use of MCDA based on Goodwin \& Wright (2004) procedures with discrete simulation to assist DMs in evaluating which D\&H transport system, as specified by its location and set of criteria, will best meet the logistics requirements of supplying sugarcane to the mills. The combined use of MCDA and discrete simulation may reduce the effort to find feasible alternatives (Brito et al., 2012), considering that the concept of simultaneously changing a set of parameters is difficult for some DMs to interpret. 
The decision-making process regarding the use of a D\&H system is verified by considering a set of performance indicators reported in literature as criteria: fleet costs (Iannoni \& Morabito, 2006; Silva et al., 2011), time spent by vehicles in transit (Iannoni \& Morabito, 2006; Higgins \& Davies, 2005; Silva et al., 2011; Lamsal et al., 2017), and the risk associated with a shortage of sugarcane to supply the mill (Junqueira \& Morabito, 2017). Even though a small number of criteria is analysed, their impact on the continuity of the system is of extreme importance as competitiveness in the commodities sector is driven by price.

\section{MATERIAL AND METHODS}

The discrete simulation model was built using the logistic processes of a sugarcane mill of a corporation located in São Paulo State. This mill operates 200 days per year with 4 mechanised harvesting fronts and currently uses the internal D\&H strategy with 31 road trains, 10 reserve semi-trailer sets, and 3 dedicated tractor units. The sugarcane processing target is $11,000 \mathrm{Mg} \cdot \mathrm{day}^{-1}$. The simulation model was built using the Arena Software v.14.7 (student version). Through the simulation model a set of feasible alternatives for evaluation by the DMs was determined.

To validate the simulation model, its performance indicators were compared with the actual system and the results were presented to the DMs to verify if the simulation model accurately represents the actual system. The corresponding durations of operations at the mill site are provided in Table 1. The DM group comprised one production manager and two supervisors, responsible for the supply of sugarcane to the mill. After model validation, we developed and conducted interviews based on multiattribute utility theory (MAUT) literature. With the interview data, we generated the utility functions and probabilities required for constructing a model of decision analysis coherent with the actual system. The preferential D\&H system scenario was analysed following the MAUT approach, as this theory effectively supports the preference of DMs in relation to decisions involving risk.

TABLE 1. Duration of operations at the mill site (Triangular distribution)

\begin{tabular}{cccc}
\hline Operation & $\begin{array}{c}\text { Minimum } \\
\text { (minutes) }\end{array}$ & $\begin{array}{c}\text { Mode } \\
\text { (minutes) }\end{array}$ & $\begin{array}{c}\text { Maximum } \\
\text { (minutes) }\end{array}$ \\
\hline Weighting & 2.0 & 3.0 & 4.0 \\
Sampling & 2.0 & 3.0 & 4.0 \\
Detaching/Attaching trailers & 1.5 & 2.0 & 3.0 \\
Unloading (per trailer) & 2.0 & 2.5 & 3.0 \\
\hline
\end{tabular}

The simulation model was built following the six steps proposed by Faria \& Silva (2015), based on Law (2007) and Banks (1998), and represented in Figure 2.

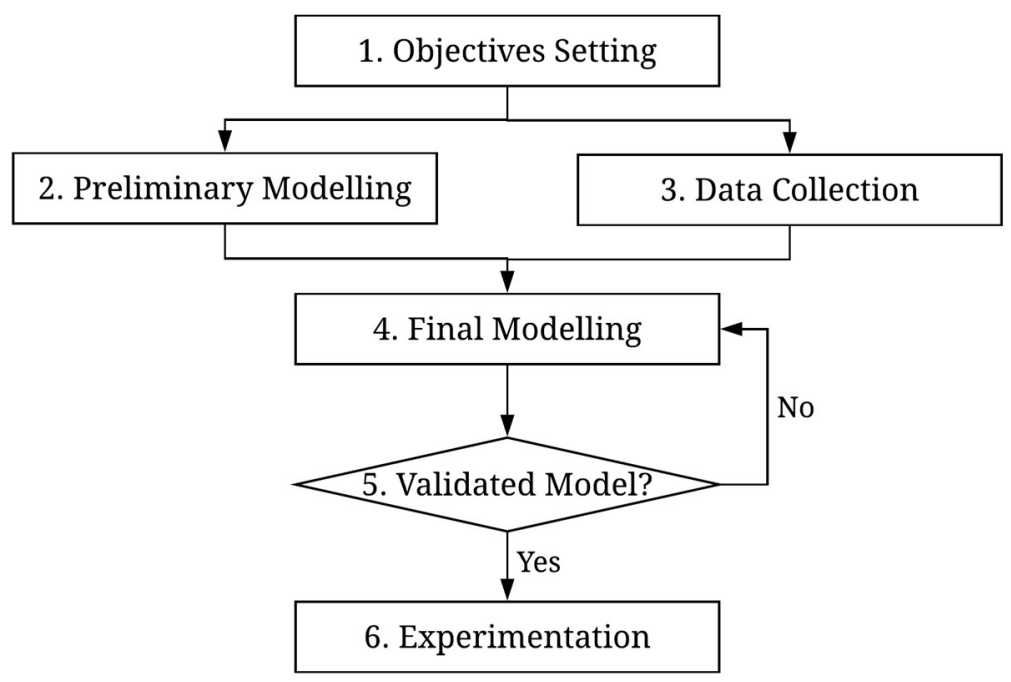

FIGURE 2. Steps of a simulation study (Faria \& Silva, 2015).

Step 1. Objectives Setting: Defines the scope and the questions to be answered by the model, the performance measures to evaluate the different system configurations, and the time frame for the study.

Step 2. Preliminary Modelling: Creates a simple model to start the study while the data are being collected and then increases its complexity as needed.

Step 3. Data Collection: Collects information about the system to be studied and data to specify the input probability distributions.
Step 4. Final Modelling: Translates the information collected so far into the final model that will be used to simulate the real-world problem.

Step 5. Model Validation: Compares the simulation results with the actual system and makes adjustments until the model accuracy is considered acceptable.

Step 6. Experimentation: Defines the alternatives to be simulated, runs the simulation, and collects the outputs of the model, enabling analysis and recommendations. 
Despite the many alternatives provided by a decision-making tool such as a discrete simulation model, a poor alternative can sometimes be chosen because it excels on a single criterion, just as a good alternative could be rejected because it is not considered adequate on a specific criterion. According to Goodwin \& Wright (2004), this is due to the limited processing capacity of the DM when dealing with complex or extensive problems. To address this issue, the multiple criteria approach using MAUT is of interest, as this technique is applicable to complex multiobjective decisions that include risk (Meirelles \& Gomes, 2009). To perform the analysis we followed the steps explained in Meirelles \& Gomes (2009) and Goodwin \& Wright (2004).

The initial interviews with DMs were conducted to establish and validate the criteria related to the 18 feasible alternatives generated by the simulation model. The alternatives included options with internal, external, and without D\&H systems as well as variations in equipment infrastructure (number of road trains, reserve semi-trailers sets and dedicated tractor units).

Figure 3 displays the resultant hierarchical tree obtained from the interviews, while Table 2 lists the descriptions and measurement units of the criteria.

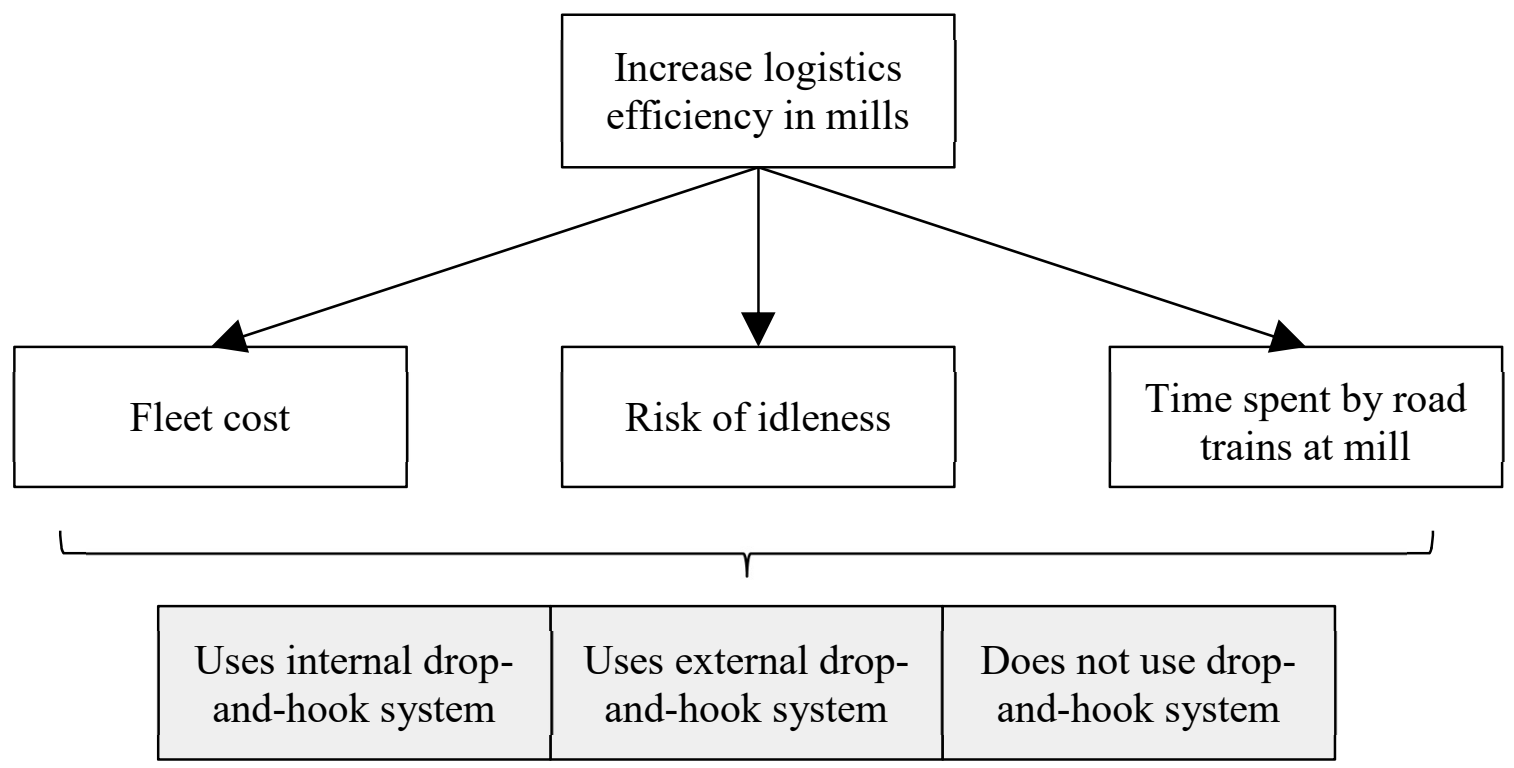

FIGURE 3. Hierarchical tree of criteria that influence D\&H configuration.

TABLE 2. Description of criteria and their measurement units.

\begin{tabular}{ccc}
\hline Criterion & Description & Unit \\
\hline Fleet cost & The combined cost of road trains, semi-trailer sets, and dedicated tractor units & Monetary (R\$) \\
Risk of idleness & Fraction of time when sugarcane stock is below & Percentage (\%) \\
$\begin{array}{c}\text { Time spent by road } \\
\text { trains at mill }\end{array}$ & $\begin{array}{c}\text { Average total time spent by road trains during operations at the mill, such as } \\
\text { attachment/detachment, weighing, sampling, etc. }\end{array}$ & Time (minutes) \\
\hline
\end{tabular}

To determine the criteria weights, we applied the swing weighting method based on the DMs' evaluation, according to Goodwin \& Wright (2004) recommendations. Once the comparison among criteria had been completed, the weights were normalised. The most important criterion, fleet cost, was assigned a weight of 0.5 , while the other two criteria were assigned equal weights of 0.25 each, totalling one. Table 3 shows the DMs' scores and their normalised weights.

TABLE 3. Scores and weights determined by the DMs for each criterion.

\begin{tabular}{ccc}
\hline Criterion & Score & Normalised Weight \\
\hline Fleet cost & 20 & 0.50 \\
Risk of idleness & 10 & 0.25 \\
Time spent by road trains at mill & 10 & 0.25 \\
\hline Total & $\mathbf{4 0}$ & $\mathbf{1 . 0 0}$ \\
\hline
\end{tabular}


Once the weights had been determined, the utility function for each criterion was plotted. Interviews were conducted to specify the preferences of the DMs by sketching their behaviour in situations involving risk (monetary or non-monetary), using successive lottery questions and a five-point scale for the utility functions (Table 4). For this, we used the certainty-equivalence approach as illustrated by the following example for fleet cost. The current annual fleet cost is $\mathrm{R} \$ 10,852.71$. According to the DM's preference, the best and worst annual cost expenditures would be at most $\mathrm{R} \$ 7,750,000$ and $\mathrm{R} \$ 23,250,000$, respectively. Suppose it is a lottery and the DM pays $\mathrm{R} \$ 7,750,000$ or $\mathrm{R} \$ 23,250,000$, each with a probability of 0.5 . Would the DM prefer the current cost of $\$ 10,852.71$ to the lottery? If the answer is 'No', the next question is if the current costs were $\mathrm{R} \$ 16,000,000$, would the DM prefer this cost to the lottery? If the answer to the first question is 'Yes', the next question is if the costs were $\mathrm{R} \$ 10,000,000$, would the DM prefer this cost to the lottery? When the DM is indifferent between the options, we continue with the questions close to the plotted curve. Note that, a variation in fleet cost from $\mathrm{R} \$ 7.75 \times 10^{6}$ to $\mathrm{R} \$ 11.63 \times 10^{6}$ generates a loss of utility of 25 units (from 100 to 75$)$, whereas a variation from $\mathrm{R} \$ 11.63 \times 10^{6}$ to $\mathrm{R} \$ 23.25 \times 10^{6}$ generates a loss of 75 units. Therefore, this behaviour demonstrates the risk aversion of the DMs.

TABLE 4. Utility functions for each criterion.

\begin{tabular}{|c|c|c|c|}
\hline \multirow{2}{*}{$\begin{array}{l}\text { Utility } \\
f(X)\end{array}$} & \multicolumn{3}{|c|}{ Criterion } \\
\hline & $\begin{array}{c}\text { Fleet cost }(x) \\
\left(\cdot 10^{6} R \$\right)\end{array}$ & $\begin{array}{c}\text { Risk of idleness }(x) \\
(\%)\end{array}$ & $\begin{array}{l}\text { Time spent by road trains at mill }(x) \\
(\mathrm{min})\end{array}$ \\
\hline 0 & $x \geq 23.25$ & $x \geq 6.3$ & $x \geq 72$ \\
\hline 25 & 19.37 & 5.25 & 60 \\
\hline 50 & 15.5 & 4.2 & 48 \\
\hline 75 & 11.63 & 3.15 & 36 \\
\hline 100 & $x \leq 7.75$ & $x \leq 2.1$ & $x \leq 24$ \\
\hline
\end{tabular}

Utility functions: $\quad f(X)=-6.45 x+150 \quad f(X)=-23.8 x+150 \quad f(X)=-2.08 x+150$

Approximated function $(0 \leq \mathrm{f}(\mathrm{x}) \leq 100)$

Using the utility functions, the alternatives' performance on all criteria was compared with V.I.S.A. (Visual Interactive Sensitivity Analysis) software. V.I.S.A. is a decision support software developed by SIMUL8 Corporation. This software assists in the modelling of discrete choice problems by applying value measures to multiple subcriteria, where decisions are modelled using a hierarchy of functions (criteria); i.e. as a decision tree. The software allowed us to check the consistency of the multiattribute utility function, and a sensitivity analysis was performed to examine the effect of changes in the weights.

An important feature of this software is its interactive interface that allows real-time scanning and verification (through trial and error) of the different priorities, values and weights of subcriteria and criteria during the robustness and sensitivity analysis. This made it possible to verify which criteria affects the selection of each of the eighteen alternatives.

\section{RESULTS AND DISCUSSION}

In this study, two sets of results were obtained. The first is the set of 18 alternatives obtained from the discrete simulation model, which was used as input to the decision analysis model. Table 5 shows all the feasible alternatives evaluated by the simulation model. The second set is the MAUT results. Table 6 and Figure 4 summarise the results obtained with V.I.S.A.

TABLE 5. Configuration of equipment used for each alternative.

\begin{tabular}{ccccc}
\hline Strategy & Alternative & $\begin{array}{c}\text { Number of } \\
\text { road trains }\end{array}$ & $\begin{array}{c}\text { Number of } \\
\text { reserve semi-trailer sets }\end{array}$ & $\begin{array}{c}\text { Number of } \\
\text { dedicated tractor units }\end{array}$ \\
\hline Internal & 1 & 31 & 10 & 3 \\
D\&H & 2 & 30 & 10 & 3 \\
system & 3 & 31 & 8 & 3 \\
\hline \multirow{3}{*}{ External } & 4 & 31 & 12 & 3 \\
D\&H & 5 & 28 & 10 & 6 \\
system & 6 & 27 & 10 & 7 \\
& 8 & 27 & 10 & 6 \\
& 9 & 28 & 8 & 6 \\
& 10 & 30 & 12 & 0 \\
Without & 11 & 31 & 0 & 0 \\
D\&H & 12 & 32 & 0 & 0 \\
system & 13 & 33 & 0 & 0 \\
& 14 & 34 & 0 & 0 \\
& 16 & 35 & 0 & 0 \\
\end{tabular}


The first four alternatives were generated to simulate the internal D\&H system. The first one is the alternative currently used by the sugar mill (reference alternative), while the second and third alternatives were used to evaluate the effect of reducing the number of road trains and reserve semi-trailer sets, respectively. The last alternative for the internal D\&H system was created to analyse the benefit of using additional reserve semi-trailer sets.

Alternatives 5 to 9 were used to simulate the external D\&H system. These alternatives were designed to produce an equivalent quantity of sugarcane milled per day as the first alternative (reference alternative), but with a different number of resources, owing to the D\&H system modification. In comparison to alternatives 1 to 4 , the number of dedicated tractor units increased owing to the longer distance covered by them to move the semi-trailers with sugarcane to the unloading point in comparison to the internal D\&H system. On the other hand, the requirement for road trains was reduced.

The last nine alternatives, from 10 to 18 , were generated to simulate the operations without a D\&H system. As with previous alternatives, we aimed to produce an equivalent quantity of milled sugarcane as the reference alternative, by varying the number of resources.

The results for the first alternative were $11,112 \mathrm{Mg}$ of milled sugarcane, $3.07 \%$ risk of idleness, and on average 51.72 minutes spent by the road trains either in processes or during idle times at the mill. The same performance indicators were evaluated for the other 17 alternatives and used as input for the utility functions to find their utility scores for the three criteria: fleet cost, risk of idleness, and time spent by trucks at the mill. The best alternatives are those that obtain the highest criteria scores. Table 6 summarises the resultant scores for each alternative and criterion.

TABLE 6. Utility scores.

\begin{tabular}{|c|c|c|c|c|}
\hline \multirow{2}{*}{ Strategy } & \multirow{2}{*}{ Alternative } & \multicolumn{3}{|c|}{ Utility score } \\
\hline & & Fleet cost & Risk of idleness & Time Spent \\
\hline \multirow{4}{*}{ Internal D\&H } & 1 & 42.61 & 76.93 & 42.42 \\
\hline & 2 & 45.51 & 69.56 & 50.72 \\
\hline & 3 & 44.54 & 11.25 & 42.26 \\
\hline & 4 & 40.67 & 100.00 & 51.32 \\
\hline \multirow{5}{*}{ External D\&H } & 5 & 43.58 & 59.08 & 92.47 \\
\hline & 6 & 43.90 & 0.00 & 100.00 \\
\hline & 7 & 46.48 & 54.09 & 96.17 \\
\hline & 8 & 45.51 & 38.85 & 82.13 \\
\hline & 9 & 41.64 & 89,79 & 91.70 \\
\hline \multirow{9}{*}{ Without D\&H } & 10 & 62.93 & 0.00 & 44.94 \\
\hline & 11 & 60.02 & 0.00 & 42.01 \\
\hline & 12 & 57.12 & 0.00 & 36.41 \\
\hline & 13 & 54.22 & 0.00 & 29.42 \\
\hline & 14 & 51.32 & 0.00 & 27.61 \\
\hline & 15 & 48.41 & 0.00 & 20.12 \\
\hline & 16 & 45.51 & 0.00 & 14.68 \\
\hline & 17 & 42.61 & 0.00 & 12.49 \\
\hline & 18 & 39.71 & 0.00 & 6.79 \\
\hline
\end{tabular}

Analysing the fleet cost criterion, we observe that the best scores (for a 0-100 ranking, where 0 is the worst and 100 the best score) are obtained by alternatives that do not use the D\&H system. This is because this system does not use any reserve semi-trailer sets or tractor units. On the other hand, considering the risk of idleness criterion, the alternatives without a D\&H system obtain the worst scores, as there is no stock on wheels available to be kept near the unloading point.

Regarding the time spent by trucks at the mills, it can be seen that the external D\&H alternatives perform better than the others, because this system prevents the trucks from wasting time on weighing and sampling activities and in the queue to unload sugarcane. Furthermore, comparing the time spent by road trains at the mill in the systems without D\&H using fewer than 32 road trains (alternatives 10 and 11) with internal D\&H systems (alternatives 1 to 4 ), it can be observed that the scores for this criterion are very similar. This can be explained by the low incidence of queues in the unloading process for alternatives 10 and 11 as a result of the reduced number of trucks in the transport system. In these alternatives without D\&H systems, trucks unload and quickly return to the farms to be loaded, but the risk of a shortage of cane is increased.

Alternative 6 has one additional dedicated tractor unit in comparison to the other alternatives, which reduces the time that trucks spend at mill in the external D\&H system. However, as alternative 6 has the smallest number of trucks but the number of reserve semi-trailer sets is maintained at 10 units, the risk of idleness increases and results in a zero score.

Figure 4 shows the final utility values for each alternative after assigning the weights for each criterion, using the scores from Table 6 and the weights from Table 3. 


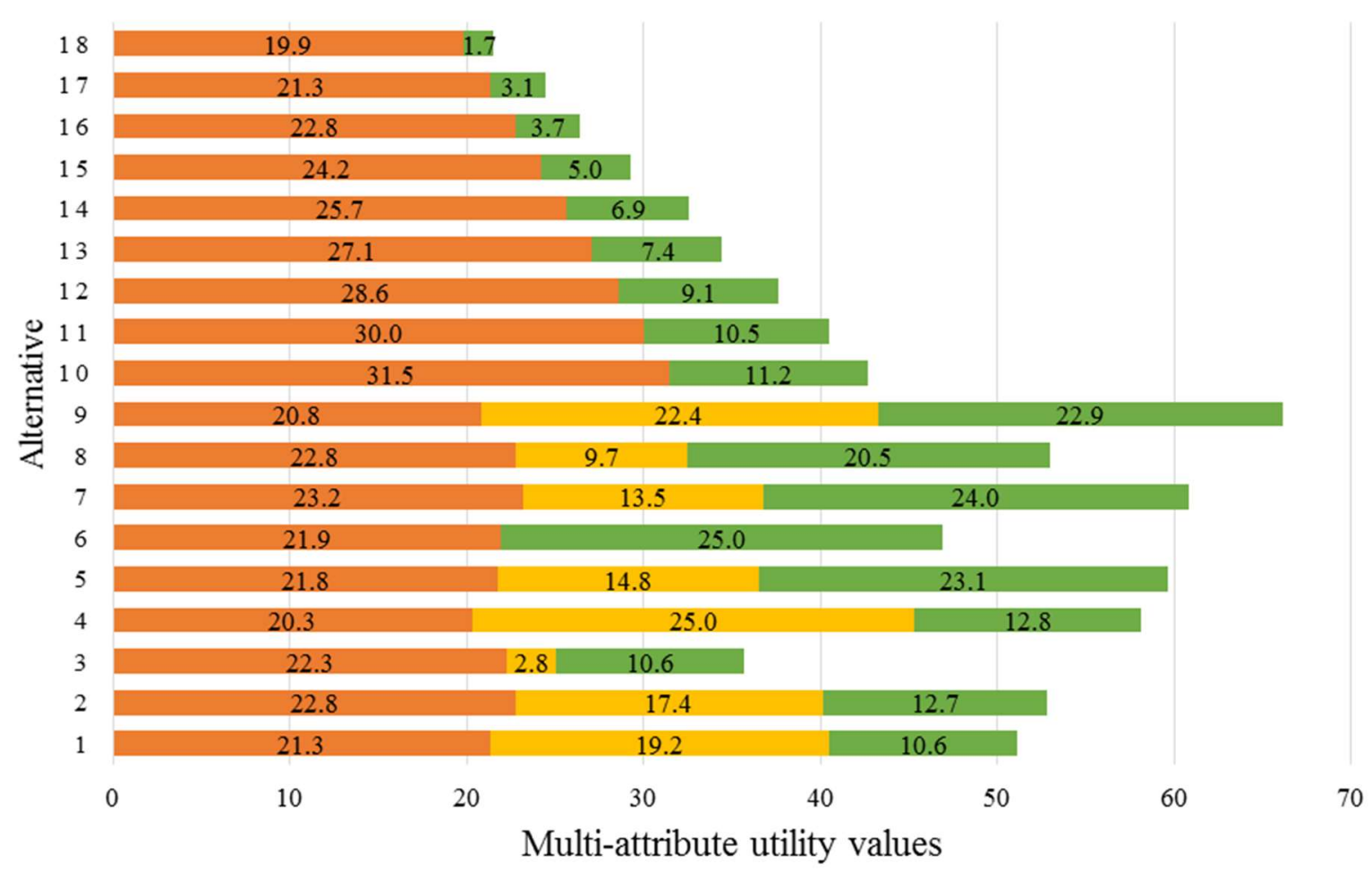

\section{$\square$ Fleet cost $\square$ Risk of idleness $\square$ Time spent}

FIGURE 4. Utility values for each alternative on all criteria.

The three alternatives that show the best results are alternatives 9, 7 and 5, in descending order, as the sums of their criteria utility values are the highest. It is worth noting that all of them use the external D\&H system. The three worst results are obtained by alternatives 18, 17 and 16, which do not use the D\&H system. These last three scenarios have a 0 utility score for the risk of idleness.

As alternative 1 is the current alternative used by the mill, we suggest the adoption of alternative 4 as a transitional option. This would increase the utility value by approximately 7 points for acquiring 2 additional semitrailer sets and would not require any changes in the current processes. Despite the increased cost of alternative 4, it obtains the maximum score for the risk of idleness, as extra semi-trailers increase the sugarcane stock. Then, when the
DMs feel comfortable to modify the process, they could exchange 3 road trains for 3 dedicated tractor units and adopt the external D\&H system, using alternative 9, which increases the utility value by another 8 points. In terms of cost, estimating that a dedicated tractor unit is equivalent to half a road train, there would be a saving of 1.5 road trains if alternative 9 was selected in comparison to the current alternative.

Concerning the sensitivity analysis, Figure 5 shows the results for the 18 alternatives where each bar represents a scenario where the weight of one of the criteria is set to zero while the black bar represents the utility value for the original weights determined by the DMs. In the sensitivity analysis, while one of the criteria had its value annulled, the other criteria had their weights increased proportionally. 


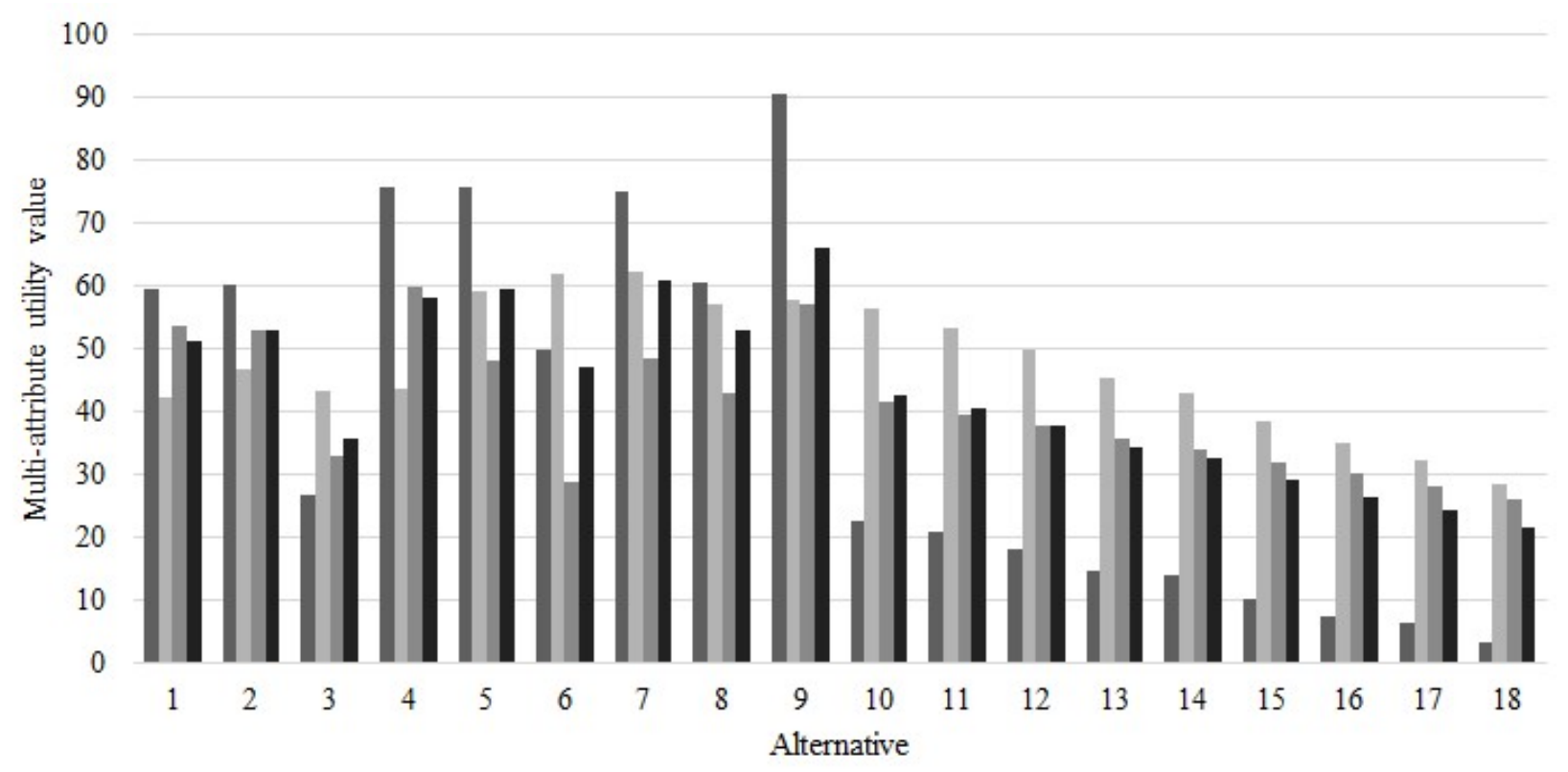

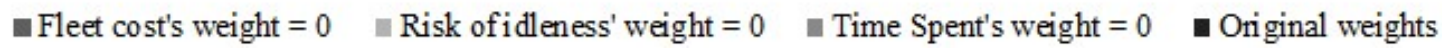

FIGURE 5. Utility values for each alternative considering different weights.

The sensitivity analysis results show that, for most of the alternatives, the utility values obtained with the original weights and those with the criterion 'Time Spent' annulled are very similar. However, for alternatives with External D\&H systems (5 to 9), the utility value with criterion 'Time Spent' annulled is considerably smaller when compared with the original utility value. Note the significant influence of the criterion related to the time spent at the mill on the results, given the difficult trade-off between 'Risk of Idleness' and 'Fleet Cost', even with the significant difference between the weights.

When the comparison is related to the criterion 'Risk of Idleness', the utility values of the alternatives without the use of D\&H systems increase largely. These results show that when idleness is not important, not using D\&H systems may be an advantage owing to the saving in purchase and maintenance costs of the smaller fleet size. Even when the risk of idleness is not considered, the alternatives with External D\&H systems are the best options because of their savings in time spent at the mills, as the truck does not go through the weighing and sampling processes and probable queuing points.

The 'Fleet Cost' is the most discrepant criterion. As the DMs initially assigned a large weight to it, its redistribution affects the results differently. We observe that when the mills need supply at any cost, the alternatives with better results in terms of time and low risk are the ones with higher utility values. Therefore, the alternatives with the most vehicles (alternatives 9,5 and 4) are the ones with the highest utility values in spite of the high investment in the fleet, given the weights chosen by the DMs.

\section{CONCLUSIONS}

This study combines MCDA and discrete event simulation to assist DMs to evaluate D\&H transport system configurations at a sugarcane mill. The best alternative corresponds to an external D\&H system with 28 road trains, 12 reverse semi-trailers sets, and 6 dedicated tractor units (alternative 9).
The fleet cost criterion has the largest impact on the results, followed by the risk of idleness criterion. According to the DMs, the cost of acquiring and maintaining the fleet is the criterion that has the largest impact on their decisions.

All alternatives using D\&H systems showed superior results in comparison with those without D\&H systems, as the D\&H systems optimize the time that trucks spend at the mill and this agility is reflected in the three criteria considered.

\section{ACKNOWLEDGEMENTS}

This study was financed in part by the Coordenação de Aperfeiçoamento de Pessoal de Nível Superior-Brasil (CAPES) - Finance Code 001 and by the Conselho Nacional de Desenvolvimento Científico e Tecnológico (CNPq) - Grants \#309516/2016-1 and PIBIC/UFSCar.

\section{REFERENCES}

Anojkumar L, Ilangkumaran M, Sasirekha V (2014) Comparative analysis of MCDM methods for pipe material selection in sugar industry. Expert Systems with Applications 41(6):2964-2980. DOI: https://doi.org/10.1016/j. eswa.2013.10.028

Banks J (1998) Handbook of simulation: principles, methodology, advances, applications, and practice. New York, John Wiley \& Sons, 864p.

Brito TB, Silva RCS, Trevisan EFC, Botter RC (2012) Discrete Event Simulation Combined with Multiple Criteria Decision Analysis as a Decision Support Methodology in Complex Logistics Systems. In: Lim, EWC (ed). Discrete event simulations - development and applications. p.105-132. DOI: https://doi.org/10.5772/50107

Cheng YR, Liang B, Zhou MH (2010) Optimization for vehicle scheduling in iron and steel works based on semitrailer swap transport. Journal of Central South University of Technology (English Edition), 17(4):873-879. DOI: https://doi.org/10.1007/s11771-010-0570-9 
Craige CC, Buser MD, Frazier RS, Hiziroglu SS, Holcomb RB, Huhnke RL (2016) Conceptual design of a biofeedstock supply chain model for eastern redcedar. Computers and Electronics in Agriculture 121:12-24. DOI: https://doi.org/10.1016/j.compag.2015.11.019

Faria LFF, Silva JEAR (2015) Effects of maintenance management procedures in sugarcane mechanic harvesting system equipment. Engenharia Agricola 35(6):1187-1197. DOI: https://doi.org/10.1590/1809-4430-

Eng.Agric.v35n6p1187-1197/2015

Goodwin P, Wright G (2004) Decision Analysis for Management Judgement. Chichester, John Wiley \& Sons, 3ed. 477 p.

Higgins A (2006) Scheduling of road vehicles in sugarcane transport: A case study at an Australian sugar mill.

European Journal of Operational Research 170(3):987-1000. DOI: https://doi.org/10.1016/j.ejor.2004.07.055

Higgins A, Davies I (2005) A simulation model for capacity planning in sugarcane transport. Computers and Electronics in Agriculture 47(2):85-102. DOI: https://doi.org/10.1016/j.compag.2004.10.006

Iannoni AP, Morabito R (2006) A discrete simulation analysis of a logistics supply system. Transportation Research Part E: Logistics and Transportation Review 42(3):191-210. DOI: https://doi.org/10.1016/j.tre.2004.10.002

Ishizaka A, Siraj S (2018) Are multi-criteria decisionmaking tools useful? An experimental comparative study of three methods. European Journal of Operational Research 264(2):1-10. DOI:

https://doi.org/10.1016/j.ejor.2017.05.041

Junqueira RAR, Morabito R (2017) Optimization approaches for sugarcane harvest front programming and scheduling. Gestão \& Produção 24(2):407-422. DOI: https://doi.org/10.1590/0104-530X1882-16
Kadwa M, Bezuidenhout CN (2015) Modelling sugarcane supply consistency at a sugar mill. Computers and Electronics in Agriculture 111:107-111. DOI: https://doi.org/10.1016/j.compag.2014.12.019

Lamsal K, Jones PC, Thomas BW (2017) Sugarcane Harvest Logistics in Brazil. Transportation Science 51(2):771-789. DOI: https://doi.org/10.1287/trsc.2015.0650

Law AM (2007) Simulation modelling and analysis. New York, McGraw-Hill, 4ed. 768p.

Meirelles CLA, Gomes LFAM (2009) O apoio multicritério à decisão como instrumento de gestão do conhecimento: uma aplicação à indústria de refino de petróleo. Pesquisa Operacional 29(2):451-470. DOI: https://dx.doi.org/10.1590/S0101-74382009000200011

Ram C, Montibeller G (2013) Exploring the impact of evaluating strategic options in a scenario-based multicriteria framework. Technological Forecasting and Social Change 80(4):657-672. DOI:

https://doi.org/10.1016/j.techfore.2012.09.019

Saravanan J, Thakkar JJ (2018) An integrated approach for lead time reduction of military aircraft major overhaul. The International Journal of Quality \& Reliability Management 35(1):2-33. DOI: https://doi.org/10.1108/IJQRM-07-2015-0102

Silva JEAR, Alves MRPA, Costa MAB (2011) Planejamento de turnos de trabalho: uma abordagem no setor sucroalcooleiro com uso de simulação discreta. Gestão \& Produção 18(1):73-90. DOI: https://doi.org/10.1590/S0104-530X2011000100006

Soliani RD, Pizzinatto NK (2015) Relationship with suppliers from the perspective of integrated logistics: the example of a Brazilian company from the sugarcane sector. Business Management Dynamics 5(4):1-9. 